\title{
"Have I kept inquiry moving?" On the Epistemology of Reflection
}

Bengt Molander, NTNU Norwegian University of Science and Technology

Email: bengt.molander@hf.ntnu.no

\begin{abstract}
Detractors of Schön's notion of "reflection in action" often point out that there is seldom time for reflection when a person is engaged in work. Such comments indicate an overly narrow conception of what reflection is. In this article it is argued that a practice, which occurs over a span of time, may be reflective without any particular activity called "reflection" being carried out. Though there is a diversity of forms of reflection in practice, it is argued that Schön's notion of "conversation" or "dialogue" can be developed so as to exhibit a structural similarity to various reflective practices. Reflection in action emerges, then, as a form of knowledge in action, as fallible as any other form of empirical knowledge.
\end{abstract}

\section{The Notion of "Reflection"}

The notion of reflection is connected with the notions of thinking and of being thoughtful. To be reflective is in general positive, and therefore the notions of reflection and of reflective practitioners turn up as key words in a large and still growing number of papers and books. Reflective teaching may be taken as one key example. Perhaps the only thing on which authors on this topic agree is that reflection is, on the whole, good. Or at least that it is bad to be unreflective. Moreover, it is common to place "action" and "reflection" against each other.

There are numerous stories about the apparent or real conflict between practical or worldly life and thinking. In Plato's dialogue Theaetetus (173-174), Socrates talks about the philosopher whose mind is not where his body is, in the city, but instead pursues its way "in the heights above the heaven" and never condescends to "what lies near at hand". Socrates tells his dialogue partner, Theodorus, the following story about Thales:

[T] hey say Thales was studying the stars, Theodorus, and gazing aloft, when he fell in a well; and a witty and amusing Thracian servant-girl made fun of him because, she said, he was wild to know about what was up in the sky but failed to see what was in front of

Copyright 2008. The author, Bengt Molander, assigns to Phenomenology \& Practice the right of first publication and educational and non-profit institutions a non-exclusive license to use this document for personal use and in courses of instruction provided that the article is used in full and this copyright statement is reproduced. Any other usage is prohibited without the express permission of the author. 
him and under his feet. The same joke applies to all who spend their lives in philosophy. (Plato, Theaetetus, 174)

Donald Schön refers to the "famous story of the centipede paralyzed by the attempt to explain how he moves" as one among several stories that suggest that reflection interferes with action (1983, p. 277).

The concept of reflection seems to have a physical sense as its origin, that is, the throwing back of light or heat. It entered philosophical language use in the seventeenth century, meaning "a reflection" of what is in the human mind to that very mind itself. The real philosophical history of the notion of reflection starts with Descartes' systematic doubt, where everything except Descartes' reflective knowledge that he thinks can be doubted. However, John Locke was the first to use the term "reflection" as a key term in his philosophical discussions. For Locke, sensation and reflection are the two sources of all our ideas (Zahn, 1992).

The Oxford English Dictionary (OED online) defines the philosophical sense of "reflection" in the following way: "The mode, operation, or faculty by which the mind has knowledge of itself and its operations, or by which it deals with ideas received from sensation and perception.” The first example cited in the dictionary comes from John Locke (1690): "By Reflection then...I would be understood to mean, that notice which the Mind takes of its own Operations, and the manner of them." My aim is not to trace the history of the various uses of the notion of reflection, but I do wish to stress two points.

First, the philosophical concept of reflection depends heavily on the notion of a (rational) mind or consciousness which can "through itself" gain knowledge or insight into its own content, structure and processes. The mind is, or can be made, transparent to itself, so to speak.

Second, there is a certain tension between identity and difference strongly connected with reflection. On the one hand, in reflection the knowing subject and the object of knowledge are or should become identical, within one single mental or intellectual movement. On the other hand, in the process a split is created between the "subject" and itself because it becomes an object for the subject. The tension between identity and difference is integral to the philosophical notion of reflection.

Since the seventeenth century, the notion of reflection is also used in ordinary language in the more general sense of afterthought or consideration. In German: "im weiteren Sinne von 'Überlegung', 'Nachdenkende Betrachtung'”' (Zahn, 1992). The Oxford English Dictionary gives the following definition of this sense: "The action of turning (back) or fixing the thoughts on some subject; meditation, deep or serious consideration"; moreover, the dictionary gives examples of still more general uses as "recollection" and "a thought or idea occurring to, or occupying the mind”.

The following definition in A Dictionary of Nursing may exemplify the use of the notion of reflection in professional practices: "the careful consideration of personal actions, including the ability to review, analyse, and evaluate situations during or after events. It is an essential part of the learning process that will result in new methods of approaching and understanding nursing practice." To make this idea more general we could just substitute "a practice" for "nursing practice”. This is a very inclusive sense. We can note that nothing here apparently depends on "reflection" as a specific kind of (mental) access of a human being to herself (or "her self”). 
An even more comprehensive sense is suggested by John Dewey when he talks about reflective experiences. The general features of such an experience are, Dewey says:

(i) perplexity, confusion, doubt, due to the fact that one is implicated in an incomplete situation whose full character is not yet determined; (ii) a conjectural anticipation-a tentative interpretation of the given elements, attributing to them a tendency to effect certain consequences; (iii) a careful study (examination, inspection, exploration, analysis) of all attainable considerations which will define and clarify the problem in hand; (iv) a consequent elaboration of the tentative hypothesis to make it more precise and more consistent, because squaring with a wider range of facts; (v) taking one stand upon the projected hypothesis as a plan of action which is applied to the existing state of affairs: doing something overtly to bring about the anticipated result, and thereby testing the hypothesis. It is the extent and accuracy of steps three and four which mark off a distinctive reflective experience from one on the trial and error plane. (Dewey, 1981, p. 504-505)

This is much wider than the most usual sense of reflection today. It is, however, worthwhile to look somewhat closer at what Dewey says. It is interesting in its own right and Donald Schön, whose ideas we will turn to in the next section, is influenced by it. For Dewey (1981), a reflected experience is connected to learning from experience, which is "to make a backward and forward connection between what we do to things and what we enjoy or suffer from things in consequence. Under such conditions, doing becomes a trying; an experiment with the world to find out what it is like” (p. 495-496). In reflection, as it were, we keep inquiry moving.

Dewey (1981) equates "thinking” and "reflection". Thinking, he says, "is the intentional endeavour to discover specific connections between something we do and the consequences which result, so that the two become continuous" (p. 500, my italics). Continuous here means continuous as we go on, in the world, in our lives. By reflection we build bridges, in our minds and in the world. Moreover, Dewey stresses responsibility and concern with the issue, "a certain sympathetic identification of our own destiny, if only dramatic, with the outcome of the course of events” (p. 501).

It seems to me that Dewey wants to pack too much into a "reflective experience". However, he is right that "reflection" makes sense only in the context of experience. It is also important, I think, that in Dewey's understanding "thinking” is not specifically "mental”. Thinking is one aspect of how we place ourselves in the world as agents and social human beings.

The various definitions or accounts we have seen so far seem to fall within one of the following three main senses:

- Reflection is everything connected to an examination, analysis, interpretation, making sense of (some part of reality), making plans for and choice of a (series of) action. (Here we can put John Dewey and A Dictionary of Nursing.)

- Reflection is thinking, especially careful thinking. (OED online and other more general dictionaries.) 
- Reflection is a human being's fully transparent access to her own mind and herself. (The philosophical tradition from Descartes, Locke and onwards.)

Certainly one can distinguish other senses of reflection and discuss how the one or the other should best be defined. I am not going into that here. My goal is to make distinctions and to find some accounts or perspectives that are useful and enlightening for an epistemology of human practices. My discussion so far is intended to give an overview of the senses of "reflection" and thereby also of reflection as a kind of, possibly complex, human activity or process. "Thinking" may fall more or less within or without each of these, depending on how "thinking” is unpacked.

\section{Schön on Reflection in Action}

In Donald Schön's books on the reflective practitioner a notion of reflection, or several, is essential, in particular what he calls, "reflection-in-action”. (Schön, 1983, 1987) Many people have questioned the notion of reflection in action. The main reason for criticism has been the fact that in acting there is in general very little time, or none at all, for reflection. Max van Manen is one of the critics. He finds an "active contemporaneous type of reflection" puzzling and talks about an active "reflective" awareness in the process of human activities. He asks: "How reflective is the active moment where the teacher is engaged with the children in his or her charge? Or how reflective can it be? And how appropriate is the image of reflection in action (thinking about doing something while doing it) as evoked by Schön and others?” (van Manen, 1995, p. 2) He answers:

In the daily life of teaching children teachers often feel that they are constantly on the spot. And in the spur of the moment only limited true reflection seems possible. It appears then that, in everyday life, the practice of pedagogy can only be reflective in a qualified and circumscribed sense.

One could even say that, ironically, in the active or dynamic situation of teaching cannot help [sic] but be "unreflective" in the curious sense that the classroom teacher must constantly act on the spot and cannot step back and postpone acting in order to first reflect on the various alternatives to this action and consequences of the various alternatives. Thus, a teacher who acts is always a dogmatist - the teacher may reflect or think about all kinds of possibilities but while acting one can only do one thing at a time. (van Manen, 1995, p. 2-3)

van Manen seems here to exclude the possibility of "true" reflection because there is not time enough or because one can only "do one thing at a time". However, at the same time he puts forward a notion of acting "thinkingly" or with "thoughtfulness":

Teachers feel that they can act with students in the classroom with more or with less thoughtfulness. While they are involved in teaching, good teachers "thinkingly act" and often do things with immediate insight. As teachers, we sometimes catch ourselves about 
to say something but then hold back before we have completely committed ourselves to what was already "on our lips." Other times the situation we are in seems to "tell" us as it were how we should act. The upshot of all this is that teacher thinking and teacher reflection is a challenging notion that needs phenomenological, philosophical, conceptual, and empirical exploration. (van Manen, 1995, p. 3)

The challenge is still with us. Donald Schön's discussion of reflection in action can take us a step forward by throwing light on the notion of (what appears to be) "immediate insight". He makes a distinction that can also, I will argue, be spelled out in terms of what a situation "tells us"-even without quotes. A situation can tell us what we in a sense already know or it can tell us what we did not know. Schön even uses the notion of a "conversation" with a situation. We turn now to Schön and his notions of knowing-in-action and reflection-in-action. Schön is much influenced by Dewey.

Schön's presentations are always built around examples or cases and his most convincing examples are from the artistic fields. One of his main examples is from a design studio in a school of architecture, where the teacher, Quist, helps the student, Petra, to progress. I will give a brief account of this example, which is discussed in detail by Schön (1983, Ch. 3; 1987, Ch. 3) before I go further into Schön's theory.

Petra's project is to design a school. She has been provided with a set of design specifications, including the dimensions and functions, and a graphic description of the site. The school should contain six classrooms, one for every year-group from one to six. The students are to work on the project throughout the term and several weeks have passed by the time we enter the picture. Petra is still at an early stage of the design. She is making preliminary sketches in order to discover a basic design, a “design hypothesis”, that she will be able to build on.

What she has realised is that the six classrooms cannot constitute the basic units of the architectural design by themselves; they are "too small in scale to do much with". The classrooms have to be put together in such a way as to provide a sense of proportion for the other parts of the construction. After her preliminary sketch she switches to arranging the classrooms in a structure of L-shaped pairs to make the basic units. She describes her aims in terms of space, orientations and their effect on education. The first and the second year-groups will be grouped together, for example, which is "more what I wanted to do educationally, anyway", Petra says (Schön 1987, p. 47). She has discovered a basic design hypothesis. It was after this that Petra got stuck. She had tried to find a good way of getting the building to fit into the site, which was a slope, but had failed.

The first part of the design review, which lasts roughly twenty minutes, consists of Petra explaining what she has done and where she has gotten stuck. Then Quist takes the initiative, he starts sketching-more as an architect than as an instructor. But he also describes what he is doing in words. Quist and Petra are not working directly with reality. This gives them a greater freedom.

Quist does not try to solve Petra's problem directly, he reshapes it—or rather he re-states the problem from its starting point. He discovers that the fundamental principle of adapting the buildings to the site is an impossible one to apply, and says: "You should begin with a discipline even if it is arbitrary, because the site is so screwy-you can always break it open later.” (Schön 
1987, p. 49) Quist then introduces a geometry to get round Petra's problems. He starts by putting in a North-South line. He continues to make sketches. He arranges the buildings in terraces.

Petra accompanies Quist on his journey of discovery through the sketches. At the end of the review they go through what has occurred, they describe and reflect upon the path that has taken them to where they are now. Petra will afterwards continue with her work, keep her own inquiry moving. On that subject the story is however silent.

Both Petra and Quist are "reflective practitioners". The case of sketching is important because sketching is, at least in the example, also thinking. They "reflect" in sketching, in thinking about the sketches and in talking with each other. There are only a few moments at the end that are labelled as "reflection" on its own, but then rather as reflection "on action" than "in action". However, the whole process is reflective in its back and forth movement. The process involves both a form of artistry and the creation of new knowledge at one and the same time. Skills, Schön says, are often manifested in the feeling the practitioner has for different situations.

We will now take a closer look at Schön's notion of "the reflective practitioner". The actions of reflective practitioners, Schön says, are characterised by knowledge-in-action and reflection-in-action. The reflective practitioners should be able to deal with situations they have not encountered before and with situations characterised by uncertainty, instability and value conflict - all of which are typical of the realities that practitioners actually encounter. (Schön, 193, p. 50) And one might add that many of the situations of everyday life are of this kind.

The skilled practitioner's knowing-in-action is characterised by reflecting-in-action, which does not mean that she is always reflecting but that she is always ready to do so. Here reflection takes place as part of knowing-in-action and simultaneously modifies it.

[B]oth ordinary people and professional practitioners often think about what they are doing, sometimes even while doing it....They may ask themselves, for example, "What features do I notice when I recognise this thing? What are the criteria by which I make this judgement? What procedures am I enacting when I perform this skill? How am I framing the problem that I am trying to solve?”. Usually reflecting on knowing-in-action goes together with reflection on the stuff in hand. There is some puzzling, or troubling, or interesting phenomenon with which the individual is trying to deal. As he tries to make sense of it, he also reflects on the understandings which have been implicit in his action, understandings which he surfaces, criticises, restructures and embodies in further action. It is this entire process of reflection-in-action which is central to the "art" by which practitioners sometimes deal well with situations of uncertainty, instability, uniqueness, and value conflict. (Schön, 1983, p. 50)

Knowing-in-action and reflecting-in-action are here both related to "thinking what one is doing"; a notion used by Gilbert Ryle in his classical discussion of "intelligent practice” (Ryle 1949, Ch. 2). Like Ryle, Schön underlines the fact that this does not mean one is doing two things, first thinking and then acting (Schön, 1983, p. 51, 54-56).

In the quotation above Schön follows Dewey in talking about reflection in a very broad and comprehensive sense, perhaps too broad and comprehensive; and perhaps also too narrow in 
his emphasis on thinking. Sometimes, however, he uses the notion in a more specific and interesting sense, with a focus on a reflective, continuous practice over time, as shown in the case of Quist and Petra.

Schön links reflecting-in-action to experimentation, which is similar to the way Dewey connects (reflective) thinking and experimentation. He puts particular emphasis on the notion of “on-the-spot-experiment” (Schön, 1983, p. 63, 308, and elsewhere in his work). This notion may be misleading, because the experiment, and the reflection, is always a process, even if it may appear as immediate and "simultaneously" modifying an action. Schön uses the concept of experiment in a broad sense: testing one's way forward in different ways (Schön, 1987, p. 68-75; Schön, 1983, p. 145-147). The carrying out of experiments means that the practitioner "becomes a researcher" in the practice context. In this process the practitioner's inquiry "is not limited to a deliberation about means which depends on a prior agreement about ends. He does not keep means and ends separate, but defines them interactively as he frames a problematic situation. He does not separate thinking from doing” (Schön, 1983, p. 68). Schön describes this process as a "conversation" - that may involve a conversation in a literal sense-in which the situation can "talk back" (we will return to that in the section on the structure and fallibility of reflection).

Schön refers to knowing-in-action as intelligent practice. This is distinguished by "on-line anticipation and adjustment" and "continuous detection and correction of error" (Schön, 1987, p. 26). This does not exclude reflection-in-action, he says. Even so, they seem to me to merge into each other. What, then, is the difference between reflection-in-action and (mere) knowledge-inaction? This is frequently unclear. At one point, however, Schön deals directly with the issue of this difference. Reflection-in-action, he says, is characterised by the fact that it reshapes our thinking and our action while we are acting:

The distinction between reflection- and knowing-in-action may be subtle. A skilled performer adjusts his responses to variations in phenomena. In his moment-by-moment appreciations of a process, he deploys a wide-ranging repertoire of images of contexts and actions. So a baseball pitcher adjusts his pitching style to the peculiarities of a particular batter or situation in a game. In order to counter an opponent's changing strategies, a tennis player executes split-second variations in play. We can say, in cases like these, that the performer responds to variation rather than surprise because the changes in context and response never cross the boundaries of the familiar. (Schön, 1987, p. 29)

The term "surprise" may sometimes be misleading. However, when we cross the boundaries of the familiar it is time for experimentation and a reframing — in action —of what we are doing. We could also put it like this: when a situation tells us something we did not (fully) know before, we play the role of researchers (in practice). This is the natural abode of reflection according to Schön.

I took some words by van Manen as a starting point for our journey through the landscape of knowing and reflecting in action. He was talking about thoughtful acting and he also used the expression "do things with immediate insight". The "immediate insight" can be a response to variation but also a response to the unexpected. Those who are experienced and who 
trust themselves can, to a considerable degree, "test their way forward" in such a way that it appears more like "immediate insight" than like testing. It may even be the case that the practitioners themselves "do not know" that they are testing their way forward. In a sense they then actually do act with immediate insight. However, they may later say something like: "This was tricky; I was not all the time sure what I was going to do.” This somewhat double answer is not paradoxical if we keep in mind that it is the continuing (learning) process that is most meaningfully called reflective, or not reflective.

Let us return once more to Quist and Petra. Both of them sketch, and through what appears in the sketches they come to see what they actually think. The sketches talk back, reflect back, in a quite literal way. "In a good process of design, this conversation with the situation is reflective”, Schön says (1983, p. 79). In answer to the situation's back-talk, the designer "reflects-in-action”. “Action” indicates, as said earlier, their activity or practice over time. The situation can tell the practitioner what she did not know or did not expect. This is I think the important thing, not whether the practitioner experienced "surprise" or not. In the case of Quist and Petra it is easy to talk about such a process as the carrying out of an experiment, testing one's way forward. The sketching is a thought experiment. It is an experiment in thinking which is also an experiment in action. Action and thinking are not separate. Therefore it is impossible to put action against thinking.

Much of what Schön says about knowing-in-action and reflection-in-action could be said without using the term "reflection”. I will now sum up some of Schön's main points and at the same time give an alternative description:

The skilled practitioner is attentive, paying attention as part of her action. She has the ability to keep several alternatives open as living possibilities in her action. Schön himself expresses this in almost the same way when instead of reflection he refers to a "double vision" that involves "the capacity to keep alive, in the midst of action, a multiplicity of views of the situation” (Schön, 1983, p. 281). The skilled practitioner also attends to what has occurred and what has not occurred and has an overview of the situation. Moreover, she has an understanding of what she has done and not done herself. This understanding need not be completely accurate; it may actually be very far from it in some cases. Normally, however, it is accurate enough. Since the skilled practitioner considers every situation to be unique, she is always prepared for unexpected events. This kind of readiness does not involve, for the skilled practitioner, any ground for uncertainty in action. She knows how to go on. In certain cases the practitioner tests her way forward-Schön calls this "experimentation". And since the practitioner is paying attention, she is also learning at the same time. In essence the skilled or "reflective" practitioner is the attentive and learning practitioner. I do not, however, rule out cases where the practitioner becomes so overwhelmed or surprised that she "does not know what to do" and gets stuck. Such situations have to be exceptions.

It is a key insight that one's own action can be the source of knowledge in action, in the course of the action itself. This is, to my mind, the most important feature of Schön's theory about reflection-in-action. One discovers what one is doing while one is doing it. And the more experienced and skilled the practitioner is, the more she can focus her attention since she is learning to see better, and the more freely her attention can roam since more and more matters are becoming routine. 
I think that Schön's notion of reflection-in-action deserves to be called a kind of reflection, a reflective process. It catches a meaning of reflection that is not covered by any of the three main senses I distinguished earlier. The theme of various kinds of reflection will continue in the next section. I will conclude this section with some remarks on the structure, or even ontology, of reflective processes, which is important for understanding Schön's notion, but not dependent upon it.

Reflection, including reflection-in-action, cannot be understood within the framework of a subject and an object. Thinking in terms of subject and object turns reflection into a form of introspection, "observation of an internal object", fully analogous to the observation of external objects. However, there is no "thing" to be grasped in reflection.

Johan Asplund, a Swedish sociologist, has argued that there always is a genuine uncertainty in communication:

I do not know what I have said until you have answered and you do not know what you have said before I have answered. You show me what I have said and I show you what you have said. (Asplund, 1987, p. 45; my own translation)

At issue here is a genuinely reciprocal interdependence, which is a source both of uncertainty and mutually improved understanding. This is an understanding in the dialogue and it exists "between" the persons involved. It cannot be understood as a relationship between a subject and an object.

I think actually the point can be made in more general terms, not only for communication but for the whole field of human action. I make the point in terms of the example with Quist and Petra. Making a slight alteration to the already quoted words of Johan Asplund: the architect (the designer) does not know what she has done or what she is striving towards until the sketch has responded; it shows her what she has done and what she is striving towards. Part of this response is through other persons, of course.

However, it should also be said that much communication, as well as much design and much of other types of practice are certain. Routine and stable forms of communication and life form the background against which the genuine uncertainty stands forth. And because of this background the uncertainty does not threaten practices as a whole. Rather it is a presupposition for learning.

Learning from what others show me is not only a learning of consequences, but as much a matter of gaining self-knowledge or self-understanding. Wilhem Dilthey stressed this in a context where he argued against introspection. I end this section with a quote from Dilthey that nicely supplements the point made by Asplund. Here "understanding" means a process of interpretation and reinterpretation in the context of a hermeneutic circle between part and whole:

The psycho-physical unit, man, knows even himself through the same mutual relationship of expression and understanding; he becomes aware of himself in the present; he recognizes himself in the memory as something that once was; but, when he tries to hold fast and grasp his states of mind by turning his attention upon himself, the narrow limits of such an introspective method of self-knowledge show themselves; only his actions and 
creations and the effect they have on others teach man about himself. So he only gains self-knowledge by the circuitous route of understanding. (Dilthey, 1979, p. 176)

\section{The Varieties of Reflection, Some Examples}

In this section I shall refer to a number of examples of reflection, or processes essentially involving reflection. I take as my starting point my own pre-understanding of reflection, which can be indicated by the following key phrases:

- a mirroring ("reflection") of a situation in which I as an agent am a part

- a mirroring of myself and my experiences

- a meeting or a confrontation with a situation in which I as an agent am a part

- a meeting or a confrontation with myself and my experiences

- making something present (without further empirical investigations)

The key terms, then, are "mirroring", "meeting" and "confrontation", all concerning myself or a situation in which I am a part. The first person form is important. My "answer" or "response" to this mirroring or meeting is an integral part of the reflection. It is essential that my answer or response should not be "forced"; it should come naturally and freely. I think this frame actually is broad enough to catch also Schön's notion of reflection-in-action. I now turn to my six examples. I only provide short descriptions, sketches. I do not think anything more is needed for my purposes in this article.

My first example comes from a $\mathrm{PhD}$-student, herself an experienced physiotherapist, carrying out a research project on experienced physiotherapists in their practices (Susanne Rosberg, private communication). One physiotherapist had told her that before every treatment she arranged the room in such a way that she had to leave the room at least once during the treatment, for example by having to fetch something needed for the treatment. She did this in order to have an excuse to leave the patient for a short time, with the goal of "seeing" where she and the patient were and how to continue. As I understand it she did not intend to make any detailed analysis, rather, she wanted to make the treatment (so far) accessible as a whole; to make present what had happened from her own point of view, which is difficult and sometimes impossible with the patient present because of the attention the patient demands. The physiotherapist arranged a meeting with herself, one could say. This situation is in some respects similar to the situation of a teacher in the classroom. The physiotherapist and her patient, however, are in closer bodily contact, where the existential closeness is as important as the physical. It is important in the example that not very much time is needed for reflection, for the physiotherapist's being with herself, a meeting with herself and her experiences.

When I once gave a talk to physiotherapists at a Swedish hospital I referred to this example and suddenly a lot of talk started among the physiotherapists. Many, perhaps most of them, had their "tricks" to free themselves from the patient and the immediate treatment situation. Moreover, it is common among physiotherapists, as among others in the health care sector, to write treatment diaries. Both the writing and the thoughts in connection with the diary 
accounts can be seen as works of reflection. This reflection, however, occurs at a greater distance, literally and in other ways, from the moment of action than the reflective moments arising during the treatment itself. Writing is making things present and making them distant at the same time.

I now turn to my second example. Some years ago a work-place studies researcher, MajaLisa Perby, carried out research on meteorologists working at a Swedish airport (Perby, 1988. I also build on some of her Swedish articles). In the background context of this study were attempts to "rationalise" the work because the employer had noticed that the meteorologists were not fully occupied with their work tasks all the time, that is, with the making of detailed forecasts. For example, when they started work they often went around looking at the maps, talking with their colleagues who had already been working for some time; often they even had time to sit down and have coffee with their colleagues. Similar things happened at other occasions during working hours. The rationalisation process was intended to streamline the meteorologists' work so that they would work only at their genuine or proper tasks. As interpreted by the employer, these tasks were those immediately involved in making forecasts with the help of meteorological theories, results of relevant measurements and advanced computer technology. During Perby's interviews with the meteorologists, one of them began to talk about "the inner weather picture" and how important it was to build up one's inner weather picture when starting a day (or night) at work, a process that continued through the working day (or night).

The notion of "inner weather picture" did not have a precise meaning from the outset. Rather, a meaning was built up by the way the expression was used in interviews and mutual interchanges between the meteorologists. Because of this very notion, the various reflections could be added to each other, individually and collectively. The notion of (inner) weather picture was or became a notion of a whole, which was needed to make sense of the data and the theories during the quite abstract, actual work of making forecasts. The need for this notion was also a need for re-entering and maintaining a certain cultural (professional) space and time, a need to be present in a certain (weather) reality as a whole. I am not going into details but one of the main themes in this example is the need for entering or constructing - and maintaining - a certain common reality. Reflection over what was essential in the understanding of weather was an important part of that. Reflection is not just "thinking” and it might very well be creative and open-ended, as the thinking in terms of the concept of inner weather picture. The inner picture was a real phenomenon and it was, in a way, constructed.

In one respect there is an obvious similarity between the two examples, as both have to do with a change of stance or focus in the activities. The physiotherapist needs to get away from the patient. The meteorologists need to get away from their strict data, their theories and the computer. Alternating stances are essential for the rhythm of their work, their "knowing in action”.

My third example is borrowed from the cabinet-maker, Thomas Tempte, who at a time was an apprentice of the boat-builder, Gösta, on the Swedish west coast. Tempte describes part of the planking process in this way: 
Gösta's advice to us apprentices did not come in the form of tables or systems but as judgement, using your senses, training the eye to make measurements, taking what you see as your starting point and always to think ahead. "All lines should be clean and harmonious; there should be no bulges to offend the eye".

The extraction of each plank from the timber, shaping it and setting it into the hull is an act of birth. Gösta appears to be ambling aimlessly round his workshop, looking at irrelevant objects, standing still for long periods, making remarks about where a particular tool has been placed, looking at the sky. His hand-rolled cigarettes are lit and then stubbed out. He goes out and rummages among the timber or just looks at it. Judging, assessing and weighing. Finally he makes up his mind. We are asked to help lift in the timber for the planking. He hums and measures, making marks with his carpenter's pencil. He takes a break for a proper smoke. This is an act of concentration. Bouts of concerted action are interspersed with moments of total relaxation. But never any haste. The haste and the effort all take place inside Gösta. (Tempte, 1982, p. 85, 87, transl. by Frank G. Perry)

This can be seen as a classical example of reflection. Again the rhythm of the working process is very important. To say that the Gösta "thinks" in the moments of reflection, when he is not physically occupied by building the boat, says very little. He probably thinks also when he is physically, "hands on", building the boat. Rather, he lets his experiences mature or "settle".

My fourth example comes from a film about Miró, the well-known painter and sculptor (I tell the story from memory). Towards the end of his working day he would hang several new canvases around in his studio. Then he took paint and brushes, walked around and made one or a few strokes on each of the canvases. How he continues the next day depends on how the figures then talk to him or how they present themselves - I do not remember the actual wording. This is an example of what Donald Schön would call a (reflective) conversation or dialogue with a situation or an object. What Miró is meeting the next day is his own expressions. The strokes express and reflect back what he began to say, in a way that also tells him something new. This is in several respects similar to Schön's story about Quist and Petra sketching in the design studio. What one is doing or has done "talks back". How Miró continues can be seen as a reflection back on a reflection (of himself and his starting points). One could also talk about a reflected (and reflecting) attentiveness, as well as about a meeting with himself.

In my fifth example, the professional photographer, Peter Gullers, in the context of judging light in photography, manually and in comparison with automatic computer-aided lightmetering, says:

Physiologists claim that the eye is a poor light-meter because the pupil automatically adapts to the intensity of light. This may be so. When faced with a concrete situation that I have to assess, I observe a number of different factors that affect the quality of the light and thus the results of my photography. Is it summer or winter, is it morning or evening? Is the sun breaking through a screen of cloud or am I in semi-shadow under a leafy tree? Are parts of the subject in deep shadow and the rest in strong sunlight? Then I have to strike a balance between light and darkness. If I am in a smithy or in a rolling mill shop, I 
note how the light coming through the sloping skylights contrasts with the sooty heat of the air in the brick building. The vibrations from hammers and mills make the floor and the camera tremble, which makes photography more difficult and affects the lightmetering. The daylight is enhanced by the red glow of the steel billets.

In the same way I gather impressions from other situations and environments. In a new situation, I recall similar situations and environments that I have encountered earlier. They act as comparisons and as association material, and my previous perceptions, mistakes and experiences provide the basis for my judgment.

It is not only the memories of the actual process of photography that play a part. The hours spent in the darkroom developing the film, my curiosity about the results, the arduous work of re-creating reality and the graphic world of the picture are also among my memories. A faulty assessment of the strength of the light and the contrasts of the subject, the vibrations and the tremors become important experience to be called next time I face a similar situation. All of these earlier memories and experiences that are stored away over the years only partly penetrate my consciousness when I make a judgement on the light conditions. The thumb and index finger of my right hand turn the camera's exposure knob to a setting that 'feels right', while my left hand adjusts the filter ring. This process is almost automatic. (Quoted from Göranzon et al., 2006, p. 15)

This is, using Schön's notions, a process where reflection-in-action and reflection-on-action interchange and together make his knowing in action develop (see Dewey's comprehensive notion of reflection). This process is "almost automatic"; that is, it may appear as if the person is acting with "immediate insight". But it can also be said to be a kind of experimentation in action; he "keeps the inquiry moving".

My sixth and last example here is an episode from when I was a rather young and inexperienced lecturer. I was working on a research project on notions of knowledge in the context of applied statistics. I was invited to give a lecture to an audience consisting of experienced statisticians working at the national Swedish statistical bureau ("Statistics Sweden”). In the first row sat one of the oldest and most well-known statisticians in Sweden at that time. I did not feel very confident. I started the presentation by saying that I was not a statistician. When I had finished my lecture the well-known statistician immediately, without a smile, asked me: "You said that you are not a statistician. What do you mean by that?"

I no longer remember what I answered. I remember, however, the feeling of an abyss opening under my feet. How could I have said something so rhetorical and idiotic? Or with the right emphasis in this context: How could $I$ have said something so rhetorical and idiotic? Who was I who could say that? The statistician's comment and question challenged my identity, both professionally and personally. I was forced to "reflect" on who I was.

\section{The Structure and Fallibility of Reflection}

My first theme here is the structure of reflection, by which I mean the structure of processes of reflection, reflective processes. It is not presupposed that there must be one and the same 
structure in all such processes. It seems to me, however, that there are two structural elements that turn up in those kinds of reflections that we have met so far. One is a certain dialogic structure: a certain kind of meeting that could not be understood as a subject-object relationship. I have already argued that. The other is that reflective processes are never complete(ed); there is never an ultimate or final result. But yet, a reflective process may allow worries to come to rest. This second structural feature leads to the second theme of this section, the fallibility of reflective processes.

So far I have written as if we could talk about "reflection" as something relatively independent of conceptions of knowledge and conceptions of a person (a human being). We have, however, reached a point where it is more fruitful to continue within the framework of a more explicit conception of human knowledge. The notion of reflection is also relatively dependent upon notions of knowledge and human beings/persons. I focus my discussion on knowledge.

I will here distinguish between representationalist conceptions of knowledge and what we can call "agent-in-the world" conceptions. A representationalist conception of knowledge conceives of knowledge in the form of certain human representations, either in the form of mental objects, most popularly beliefs (about the world), or in the form of linguistic representations, most popularly statements, systems of statements and other symbolicmathematical structures. I will not argue here generally against representationalist accounts, even though I believe that the prospects are not good for an understanding of reflective knowledge as a representationalist form of knowledge or for understanding reflective knowledge from the standpoint that knowledge in general is representational. Instead I turn to a nonrepresentationalist form of knowledge; an agent-in-the world conception of knowledge.

Donald Schön is, as I see it, somewhat divided. His basic account in terms of knowing-inaction and reflection-in-action is essentially a non-representationalist account but he does give a representationalist interpretation of formulated knowledge in action and reflection on action. This is obvious for example when he talks about describing "reflection-in-action itself" (1983, p. 276) and "the ladder of reflection" (1987, p. 114-117). Here, however, I will focus only on a non-representationalist reading or understanding of Schön. It is important to note that a representationalist account of knowledge sees representations as the essential medium of knowledge; a non-representationalist account may very well give the use of certain representations an important role in knowledge formation, without seeing them as essential to knowledge.

I take as my starting point the claim that knowledge primarily exists only in the form of skilled and insightful agents in the world. Knowledge is something that leads us in and through the world. The inspiration for this account comes very much from the pragmatist philosopher, William James (1978, 1907). I will very briefly indicate some basic features of his account of "truth”, which I read as an account of knowledge.

The key element in James is that knowledge (in action) is something that leads us through the world in various ways and that it is not possible to determine a "single measure of truth”. What we humans are seeking to determine and the only thing we can seek to determine is how well something leads us. It is not assumed that the ends are given independently of this knowledge. This is clearly not the case in James' pragmatism, which becomes clear when he 
talks about religious beliefs, for example (1978, Lect. III, esp. p. 56, 62). James does not have a purely instrumental view of knowledge even though it may appear so on occasion. Knowledge is what leads us in the best way in a comprehensive sense, not necessarily towards a predetermined end. And what is better than something else is itself an object of knowledge.

Knowledge, then, following James (1978), is what works best in the way of leading us or guiding us through the world; what works best in the long run and on the whole "of course" (p. 106). Taken together, the route and the goal should constitute a maximally satisfactory intercourse with the world, in an almost total sense. Put concisely, knowledge is what leads to the best. Professional skills do not make up an "instrument" to achieve a goal that can be defined irrespective of the activity concerned. Knowledge and ethics — that is, "the striving for the best" - are intrinsically connected with one another.

Let us return to the notion of conversation or dialogue. As I said, it is easy to "read" most of what Schön says about knowing-in-action and reflection-in-action from the point of view of an agent-in-the-world epistemology. Knowing-in-action and reflection-in-action are most basically seen as a dialogue (as in Schön, 1988) or a conversation (as in Schön,1983; 1987) with a situation. For Schön the notion of conversation or dialogue-which word is used does not seem to matter-captures an important aspect of all knowing-in-action. The idea of the dialogical is used to reveal a structure of meaning in which the relation between those who "converse" is not a relation between subject and object, but rather, between two subjects or between a subject and the (unobjectified) totality of which she forms a part. Consider the dialogical relationship between the meteorologists and their "weather picture" in the previous section; it also encompasses, in a broader sense, a dialogue or a conversation with the weather.

The process whereby Quist and Petra form knowledge has a dynamic, dialogical structure. This is shown on several levels: in the dialogue between Quist and Petra-where the "language" covers both sketching and talking - as well as in the interchange between part and whole and the interaction between commitment and detachment. The conversation acquires both its meaning and its dynamic structure in this interplay between several levels. The alternation between commitment and detachment also applies to the individual's own work, in the relation of the individual to her own sketching. The work - and the formation of knowledge-involves an alternation between leading the sketching and opening oneself up to allow the sketches to talk, so that the unintentional and the uncontrolled may also make themselves known.

The sketching is an experiment in thinking, a "thought experiment" that is also an experiment in action, as well as the other way around. The intentions and the ends are developed as part of this process. They are not given ready-made in advance. This is one of the things that make the notion of the conversation so apt (Schön emphasised this very point in a lecture in Gothenburg, 1992, December 13).

The structure of knowledge, learning and reflection are dialogical. We can see that on at least three levels: (i) the individual in relation to her sketch and her sketching, (ii) the relation between the persons, and (iii) the relation between the individual and the whole situation in which she is part. All of these are related to each other as parts-wholes in a hermeneutic circle. One could also try to add a fourth level, that between sketch and reality, but that would have to refer to the persons involved if we are not to end up in a purely representationalist account of language and knowledge. Rather, we seem to be back at the interplay between (i), (ii), and (iii). 
That the sketching and design situation is reflective means that the designer does not know what she has done or what she is striving for until what she has been doing has responded. It shows her what she has done and what she has been striving for. This involves both a creation of meaning and an experiment. It is not presupposed that there exists for the person herself, or anybody else, infallible or fully transparent access to what she has done. It may, for example, also be necessary to carry out an empirical investigation in order to clarify the course of events. Or some extra thinking may be needed without an immediate demand or obligation to act. Experiences may need time to settle.

The sketching is an obvious example of how a "conversation” proceeds. However, there is nothing exclusive to sketching here. In other fields the "sketching" - the conversation-may take place in words, or in some other symbolic medium. In order to see conversation in the same way that Schön does-and I do-the context of action has to be seen as a context of meaning that is not fully determined in advance. This necessitates some form of symbolic medium, which may even be nature or the world as whole meaning structures. All intentional action is part of a context of meaning of this kind; among the reasons for this is that language is a constitutive part of action.

Whether or to what extent "conversation" or "dialogue" is to be understood literally does not seem to me to be a good question. However, to say that a situation "is" a conversation does not exclude that it "is" at the same time very many other things. At some point, Schön says that we "engage in a continuing conversation with the larger societal situation of which we are a part" (Schön, 1983, p. 347). This sounds all very well but one would have to study different cases in more detail to determine how apt the use of "conversation" is here. There is, for example, a certain symmetry in a conversation. In particular social or civic contexts, other expressions may be more appropriate, such as our being "prisoners of society" or "cogs in a machine". "Conversation" manages to capture one element but excludes others. Naturally this also applies within the design studio.

The way I read Schön and the way I understand an agent-in-the world conception of knowing in action in the broadest possible sense is informed by an overall non-objectified and hermeneutic approach to human beings in practices. However, in processes of reflection it is often useful to objectify some aspects of situations and sometimes, even whole persons. And it may be useful to "subjectify", to make the subject the one who decides "what there is". Such changes in perspective are movements in a reflective process of learning in action. The most important thing is the result of the alternating and changing stances within a process where we want to learn more about what-we-are-and-do-in-the-world.

I have emphasized reflection in action, but at the same time, I have tried to exhibit a wide variety of reflective processes. From a phenomenological point of view, to refer to the Oxford English Dictionary again, reflection is often connected with "the action of turning (back) or fixing the thoughts on some subject; meditation, deep or serious consideration.” This, however, is just a possible starting point for reflective processes. Moreover, it may not always be better to think "more" or "more deeply" but rather, in other ways, ways that open the world and guide us in it. Let us return to the example about the centipede in the first section above. If the centipede thinks more and more deeply about how it moves with all its feet it will, we assume, only get into more trouble. However, as Schön says: “Certain descriptions are more useful for action than 
are others. The centipede might have given the nonparalyzing answer to the question, 'How do you do it?' by saying simply, 'I move forward in a wavy motion.”’ (Schön, 1983, p. 279)

The idea that reflection is self-validating, which is typical in the tradition that considers reflection as persons' rational and transparent access to themselves, appears to me to be an epistemological non-starter. Results of processes of reflection are not infallible. Of course, sometimes it is impossible to doubt results of what we phenomenologically should label "reflection". But there are many things that we do not and perhaps indeed cannot (genuinely) doubt (see Wittgenstein, 1974).

We then return to the idea of knowledge or knowing from the point of view of agents in the world, agents in conversation with each other and with situations in the world. What is better and what is worse knowledge is shown by how well it leads us or guides us through the world (in our practices, in our life). Knowledge is, to put it briefly, what leads us in the best way and towards the best-in the long run and on the whole, of course. In this never-ending process many aspects of learning and knowledge formation come into play: ascertaining facts, analysing concepts, analysing situations etcetera-something like Dewey's conception of reflective experiences. Of course, all kinds of "reflection" may be included in this process of knowledge formation, which may also include degeneration of knowledge. Reflections prove their worth within the framework of how we carry on our practices in the world, learning how to better go about being in the world. Many things are important, not least the alternation between various stances (for example part-whole, commitment-detachment). A skilled practitioner is also skilled at alternating - the right way at the right time. This has much to do with rhythm and the "feeling" for the situation and where it is leading. And if we ask how the worth of the alternation may be proved, we have already gone full circle. There is no other answer than the one we already have given: knowledge is what, as a whole and in the long run, leads to the best. This is, of course, a never-ending journey. We keep inquiry moving (see Schön, 1983, p. 133, from where I borrowed the title of my paper).

\section{Reflection as a Key Word; By Way of Conclusion}

In what sense, if any, is a reflective (reflected, reflexive) practice, of one kind or another, better than a non-reflective practice of the same kind, if there is such a thing? First, I have argued that because reflection is as fallible as other ways of gaining knowledge, it is not at all certain that a reflective or reflected practice is better than a non-reflective one. It depends on how well the reflection processes have managed to improve the overall knowledge (in action) of the agent(s) in question. Reflection is best seen as a kind of knowing in action (with or without hyphens).

The examples I have used exhibit some of the variety and complexity of reflective processes. However, they are also intended to show that "moments of reflection" are necessary in order to carry out practices in a way that is good for people. Reflection has very much to do with time and rhythm and, I should add here, presence in a practice or in a situation, presence for others and for oneself. Several times I have used the term "meeting" to refer to such moments of presence. Sometimes you may need only a few reflective moments. In other cases you may need to settle things with yourself-at least with yourself, and possibly with others, as well. This may 
take time, sometimes a very long time. A main idea of reflection is a meeting or confrontation with yourself and your experiences, not least through how others see you and your experiences. Sometimes a precondition for a meeting with oneself is that there should be no necessity of acting immediately (or immediate action). However, what is immediate or not depends very much on the practice in question. And an emergency situation may really make a person meet her limits, and therefore, herself.

If there could be a phenomenology of reflection, it must proceed essentially by examples. Is there anything that may be called "phenomenological reflection"? Yes, I think there is, but again, no type of reflection can claim infallibility. And there is never only one true or proper description.

Reflection is not an aim in itself. Reflection is not self-validating or self-justifying. However, practices that do not allow space and time for reflection will probably end up as nonlearning practices. A learning practice needs practitioners who can be reflective at the right time, and at best, only at the right time. But stop for a moment! Reflect! Knowledge is not only gained by the foreseeable and the rational. We may learn from horrible mistakes, satirical jokes, unfair comments and unpleasant behaviour and many, many other things. An epistemology of action is also a politics of action (Molander, 2002). Therefore, I think Schön's moral, if we should call it a moral, that we should keep inquiry moving, is perhaps the best way of saying something general about reflection. This is a pragmatist moral in the tradition of James and Dewey.

\section{References}

Asplund, J. (1987). Om hälsningsceremonier, mikromakt och asocial pratsamhet (On greeting ceremonies, micro-power and asocial talkativeness). Göteborg: Korpen.

Dewey, J. (1981). Experience and thinking. In McDermott, J.J. (Ed.). The philosophy of John Dewey. Vol. I-II (in one volume), p. 494-506. (Originally in Democracy and Education, 1916.) Chicago and London: The University of Chicago Press.

Dictionary of Nursing. Oxford University Press, 2003. Oxford Reference Online. Oxford University Press. Retrieved 23 April 2008 from http://www.oxfordreference.com

Dilthey, W. (1979). The delimitation of the human studies. In Rickman, H.P. (Ed. and transl.). Dilthey selected writings, p. 170-176. Cambridge: Cambridge University Press.

Göranzon, B. (2006). The practice and the use of computers: A paradoxical encounter between different traditions of knowledge”. In Göranzon, B., Hammarén, M. \& Ennals, R. (Eds.). Dialogue, skill and tacit knowledge, p. 9-21. Chichester: Wiley.

James, W. (1978). Pragmatism. In Pragmatism and The meaning of truth. Cambridge, Mass.: Harvard University Press. (Originally published 1907.) 
Molander, B. (2002). Politics for learning or learning for politics? Studies in Philosophy and Education, Vol. 21, p. 361-376.

Oxford English Dictionary Online (OED online). Oxford: Oxford University Press 2008. Retrieved 23 April 2008 from http://dictionary.oed.com

Perby, M.-L. (1988) Computerization and skill in local weather forecasting. In Göranzon, B. \& Josefson, I. (Eds.). Knowledge, skill and artificial intelligence, p. 39-52. London: SpringerVerlag.

Plato. Theaetetus. Transl. by M.J. Levett, rev. by M. Burnyeat. In Cooper, J.M. (Ed.), Plato complete works (1997), p. 157-234. Indianapolis/Cambridge: Hackett.

Ryle, G. (1949). The concept of mind. London: Hutchinson’s University Library.

Schön, D. A. (1983). The reflective practitioner. How professionals think in action. New York: Basic Books.

Schön, D. A. (1987). Educating the reflective practitioner. Toward a new design for teaching and learning in the professions. San Francisco and London: Jossey-Bass.

Schön, D. A. (1988). Designing: rules, types and worlds. Design Studies Vol. 9, s. 181-190.

Tempte, T. (1982). Arbetets ära (The honour of work). Stockholm: Arbetslivscentrum.

van Manen, M. (1995). On the epistemology of reflective practice. Teachers and Teachings: theory and practice, 1, pp. 33-50. Retrieved 2 July 2008 from http://www.phenomenologyonline.com/max/articles/epistpractice.html

Wittgenstein, L.(1974). Über Gewissheit/On certainty. Transl. by D. Paul, D. \& G.E.M. Anscombe. Oxford: Basil Blackwell.

Zahn, L. (1992). Reflexion. In Ritter, J. \& Gründer, K. (Hg.) (1992). Historisches Wörterbuch der Philosophie, Band 8, p. 396-406. Darmstadt: Wissenschaftliche Buchgesellschaft. 